\title{
THE ENERGY-LINE METHOD IN THE MECHANICS OF AVALANCHES
}

\author{
$B y$ H. J. KÖRNER \\ (Bayerisches Geologisches Landesamt, Prinzregentstrasse 28, 8000 München 22, Germany)
}

\begin{abstract}
The energy-line method results from the graphical representation of the energy law as applied in hydraulics. It makes it easier to understand the entire process of the movement of an avalanche from where it breaks away to where it is deposited. The technique, the energy lines, and the average slope of avalanches, as well as the theoretical energy lines of the one-coefficient and two-coefficient models of avalanche dynamics, are described. The method is explained by means of an example.

RÉsumé. La méthode des lignes d'énergie dans la mécanique des avalanches. Le procédé dit des "lignes d'énergie" est une représentation graphique du théorème relatif à l'énergie, un graphique qui rend plus facile la compréhension du mouvement des avalanches, sur la totalité de leur cours, depuis leur début jusqu'au dépôt final. Le processus et les lignes théoriques d'énergie du modèle à un et à deux coefficients de la dynamique des avalanches font l'objet d'une description. De plus, le procédé est commenté sur la base d'un exemple.

Zusammenfassung. Die Energielinienmethode in der Lawinendynamik. Das Energielinienverfahren ergibt sich aus der in der Hydraulik üblichen graphischen Darstellung des Energieerhaltungssatzes. Es erleichtert das Verständnis der Lawinenbewegung im ganzen Ablauf vom Anbruch bis zur Ablagerung. Die Verfahrensweise, die Energielinien und das Pauschalgefälle von Lawinen sowie die theoretischen Energielinien des Einund Zweikoeffizientenmodelles der Lawinendynamik werden beschrieben. An einem Beispiel wird das Verfahren erläutert.
\end{abstract}

\section{THE ENERGY LINE OF A FLOWING SNOW AVALANCHE}

In Figure $\mathrm{I}$, an avalanche occurrence is illustrated by means of a profile of the path of the avalanche, the top left-hand corner of the figure being taken as the break-away point of the avalanche. Accelerated by gravity, the masses travelled down-hill on the steep sections and, braked in flatter parts of the slope and by other obstacles, were deposited at the foot of the slope. The movement involved is a non-steady state process (owing to the continuous change in the magnitude of accelerating and braking forces) and also non-uniform (as narrowing and widening and changes in the height of the flow alter the flow crosssection). The total mass, the density of the snow, and the flow-resistance coefficients also change, as a rule, in the course of the movement.

It is difficult to take stock of and calculate the totality of these complicated processes. With the help of the energy-line method, the entire course of the movement can be made easier to understand. In this method, the flow height $D_{\mathrm{f}}$ of the avalanche snow is entered on the longitudinal profile of the slide path (line $\mathrm{A}^{\prime} \mathrm{B}^{\prime} \mathrm{PTC} \mathrm{E}^{\prime}$ in Fig. I) at point any $\mathrm{P}$ as a line $\mathrm{PQ}$ normal to the path, and the velocity head $h_{v}{ }^{\prime}$

$$
h_{v}^{\prime}=v^{2} / 2 g \text {, }
$$

as a line QL vertically above $\mathrm{Q}(v$ is the flow velocity at the point $\mathrm{P}$ on the path, and $g$ the acceleration due to gravity $\left.=9.8 \mathrm{I} \mathrm{m} / \mathrm{s}^{2}\right)$. The point $\mathrm{L}$ which is thus obtained lies on the energy line. The flow height $D_{\mathrm{P}}$ is usually much smaller than the velocity head and can then be neglected.

The energy line results from the graphical representation of the law of the conservation of energy, as is familiar in hydraulics. Applied to avalanches, this law states that for any point $\mathrm{P}$ on the path, the sum of potential energy (due to elevation) plus kinetic energy (the velocity head) plus energy losses which occur (the energy-loss head) is constant. The energy-loss head $\Delta h^{\prime}$ (the line LK in Fig. I) is that part of the original overall energy, shown in Figure I as energy head $H_{\mathrm{A}}^{\prime}$ of the initial position of rest, which is dissipated on the way from $\mathrm{A}^{\prime}$ to $\mathrm{P}$, i.e. is no longer convertible into velocity. The energy losses determine how the energy line runs.

From measured values for flow height $D_{\mathrm{f}}$ and flow velocity $v$ of avalanches, continuously falling, more or less dipping, sometimes undulating curves, or even curves with kinks (see, for instance, the dashed-line curve in Fig. 2a) are obtained as energy lines. In those cases when the slide path has little dip, these lines can usually be replaced by a straight line. 


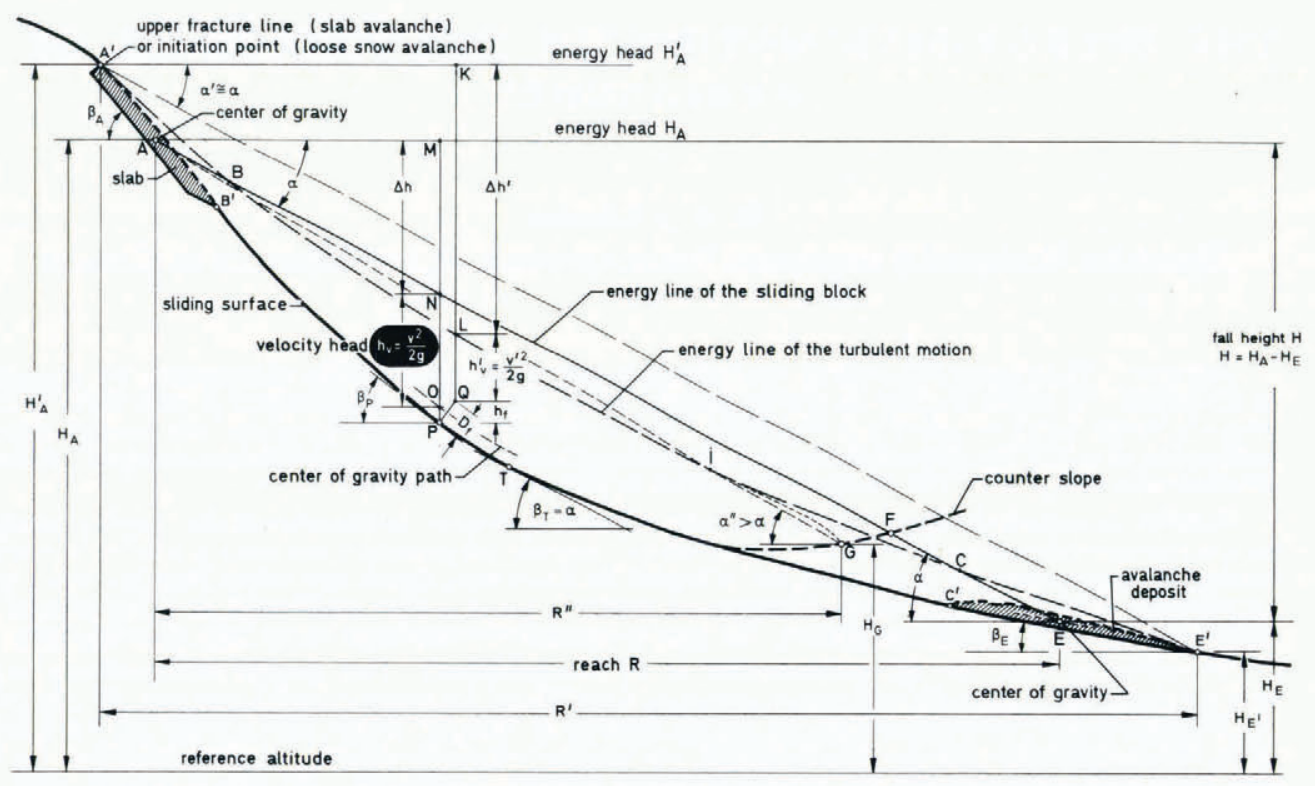

Fig. I. Avalanche-path profile with the energy lines for the one-coefficient and two-coefficient models.

THE ENERGY LINE OF THE ONE-COEFFICIENT MODEL

For a rigid body like a sled which slides over the slide path with a constant coefficient of friction $f_{\mathrm{r}}$, a straight energy line corresponding to the line AE in Figure I at an angle $\alpha$ to the horizontal is obtained (Heim, 1932). The points A and E mark the position of rest of the centres of gravity of the plunging mass before and after the plunge. The velocity $v$ of the sled for every point on the path is particularly easy to determine with this straight energy line AE. By measuring to scale the distance ON in Figure $\mathrm{I}$, i.e. the distance between the path of the centre of gravity and the energy line AE, as the velocity head $h_{v}$, it is possible to obtain

$$
v=\left(2 g h_{v}\right) \text {. }
$$

The slope angle $\alpha$ of the straight energy line AE was designated by Heim (1932, p. I 13) the "centreof-gravity slope" and the tangent of this angle $\alpha$

$$
\tan \alpha=H / R=\text { fall height } / \text { reach, }
$$

Scheller (unpublished) called the "average slope". Geometrically, the average slope is the mean slope of all curves connecting the points A and E. Physically, the average slope is equivalent to the constant coefficient of friction $f_{\mathrm{r}}$ between the sled and the slide path:

$$
\tan \alpha=f_{\mathrm{r}}
$$

(Heim, 1932; Scheidegger, 1973; Körner, 1977). Empirical values of $\alpha$ can be used to determine the reach $R$ of the movement by plotting a line making an angle $\alpha$ to the horizontal from the starting point A. The terminal point $\mathrm{E}$ of the movement of the sled is always where the centre-of-gravity path (or the slide path as an approximation) intersects the energy line. On a counter-slope, the movement would thus terminate at point $\mathrm{F}$ in Figure $\mathrm{I}$ at the latest, and probably sooner, roughly at point $\mathrm{G}$.

\section{The AVerage slope of avalanches}

In the case of avalanches with a free run-out, the slope angle $\alpha$ of the centre-of-gravity straight line $\mathrm{AE}$ is adequately equal to the slope angle $\alpha^{\prime}$ of the line $\mathrm{A}^{\prime} \mathrm{E}^{\prime}$ in Figure $\mathrm{I}$. The line $\mathrm{A}^{\prime} \mathrm{E}^{\prime}$ is designated the "travel slope" (Heim, 1932, p. I I3). A' is the highest breakaway point and $\mathrm{E}^{\prime}$ is the furthest 
removed terminal point of the deposit. These two points can always be unambiguously determined on the terrain. The average slope

$$
\tan \alpha \approx \tan \alpha^{\prime},
$$

is the first and most important factor determining any avalanche descent because, by analogy with the sled model, it provides empirical data on the reach and run-out distance and initial pointers to the velocity of avalanches. It is on this account that the energy-line method is chiefly used for avalanche dynamics.

The average slope $\tan \alpha^{\prime}$ of large snow avalanches is between 0.3 and $0.6\left(\alpha=17-31^{\circ}\right)$, usually between 0.4 and $0.5\left(\alpha^{\prime}=22-27^{\circ}\right)$. These figures depend on the snow conditions, the volume of descending snow, and the properties of the path (shape of the profile, roughness, etc.). Empirical figures for snow avalanches are given by Lied and Bakkehøi (1980).

\section{The ENERGY LiNES AND COEFFICIENTS OF THE VOELLMY MODEL}

With smooth-transition slope paths, predominantly concave dipping energy lines corresponding to the line $\mathrm{A}^{\prime} \mathrm{BLiCE}$ ' in Figure I are obtained for the two-coefficient model of Voellmy (1955). These curves are obtained section by section, as described by Körner (1976), with the help of the equation:

$$
\left.v_{i+1}=\left[v_{\mathrm{E} i}{ }^{2}-\left(v_{\mathrm{E} i} i^{2}-v_{i}{ }^{2}\right) \exp -2 \Delta s_{i} / k_{i}\right)\right]^{i},
$$

where $v_{i}$ is the velocity at path station $i, v_{i+\mathrm{I}}$ the velocity at the path station $i+\mathrm{I}, \Delta s_{i}$ the length of section $i$ between path station $i$ and $i+\mathrm{I}$,

$$
v_{\mathrm{E} i}=\left[D_{\mathrm{f} i} \xi\left(\sin \beta_{i}-\mu \cos \beta_{i}\right)\right]^{\mathbf{i}},
$$

and represents Voellmy's equation for terminal velocity on a path with constant slope $\beta_{i}, D_{\mathrm{f} i}$ is the mean flow height in section $i, \beta_{i}$ the path slope in section $i, \mu$ and $\xi$ are the coefficients of the Voellmy model, and $k_{i}=D_{\mathrm{f} i} \xi / g$ is the characteristic flow length in section $i$.

In Equation (6), the second term in the brackets acts as a corrective term to Equation (7) for short sections $\Delta s$ of a bending path within which the variables $\beta, D_{\mathrm{f}}, \mu$, and $\xi$ can be assumed to be constant. For the final path section $\Delta s_{\mathrm{u}}$, that is to say for the so-called run-out distance, it follows from Equation (6) that

$$
\Delta s_{\mathrm{u}}=\frac{D_{\mathrm{fu}} \cdot \xi}{2 g} \ln \left[\mathrm{I}-\frac{v_{\mathrm{u}^{2}}}{v_{\mathrm{Eu}}{ }^{2}}\right] .
$$

For every possible terminal point $\mathrm{E}^{\prime}$ of an avalanche, there is a set of related pairs of values for the coefficients $\mu$ and $\xi$ ( $\mu$ being the sliding friction coefficients and $\xi$ the flow-resistance coefficient). For each of these pairs of values of $\mu$ and $\xi$ an energy line and a velocity distribution along the path can also be calculated (see Fig. 2). For $\xi \rightarrow \infty$ the two-coefficient model changes into the sled model.

When the calculated velocity distributions are compared with the velocities measured in Nature, the significant pair of coefficients $\mu$ and $\xi$ for the overall process can be assessed.

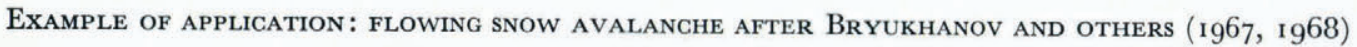

Flowing snow avalanche No. I triggered by mortar shell explosions on 30 March 1965 was selected as an example, because very precise photogrammetric measurements of the front velocities of this avalanche by Bryukhanov ( $1967, \mathrm{Ig} 68$ ) are available. Involving a volume of $10000 \mathrm{~m}^{3}$, this is also the largest avalanche measured by Bryukhanov. The path profile and the velocities measured were taken from the 1967 paper. Unfortunately, Bryukhanov provides no information on the flow heights of this avalanche. For this reason, a flow height of $D_{\mathrm{f}}=\mathrm{I} \mathrm{m}$ was assumed for the calculations. As can be seen, the path profile shown in Figure 2 is a rather gentle slope in the upper part and then starts to dip more steeply. The measured velocities are shown in Figure $2 \mathrm{~b}$ as a dashed, undulating line. These measured velocities are used to work out the energy line shown as a dashed line in Figure $2 \mathrm{a}$.

All avalanches measured by Bryukhanov exhibit this conspicuous pulsation of the front velocities. Owing to unevennesses in the path, the calculated velocity curves admittedly also undulate slightly along the path, as can be seen from Figure $2 b$. However, the measured front velocities obviously show a great deal more pronounced a reaction and the frequency is out of phase with calculated velocity fluctuations. This phenomenon points to a complication which cannot be covered by the available models for avalanche dynamics. 

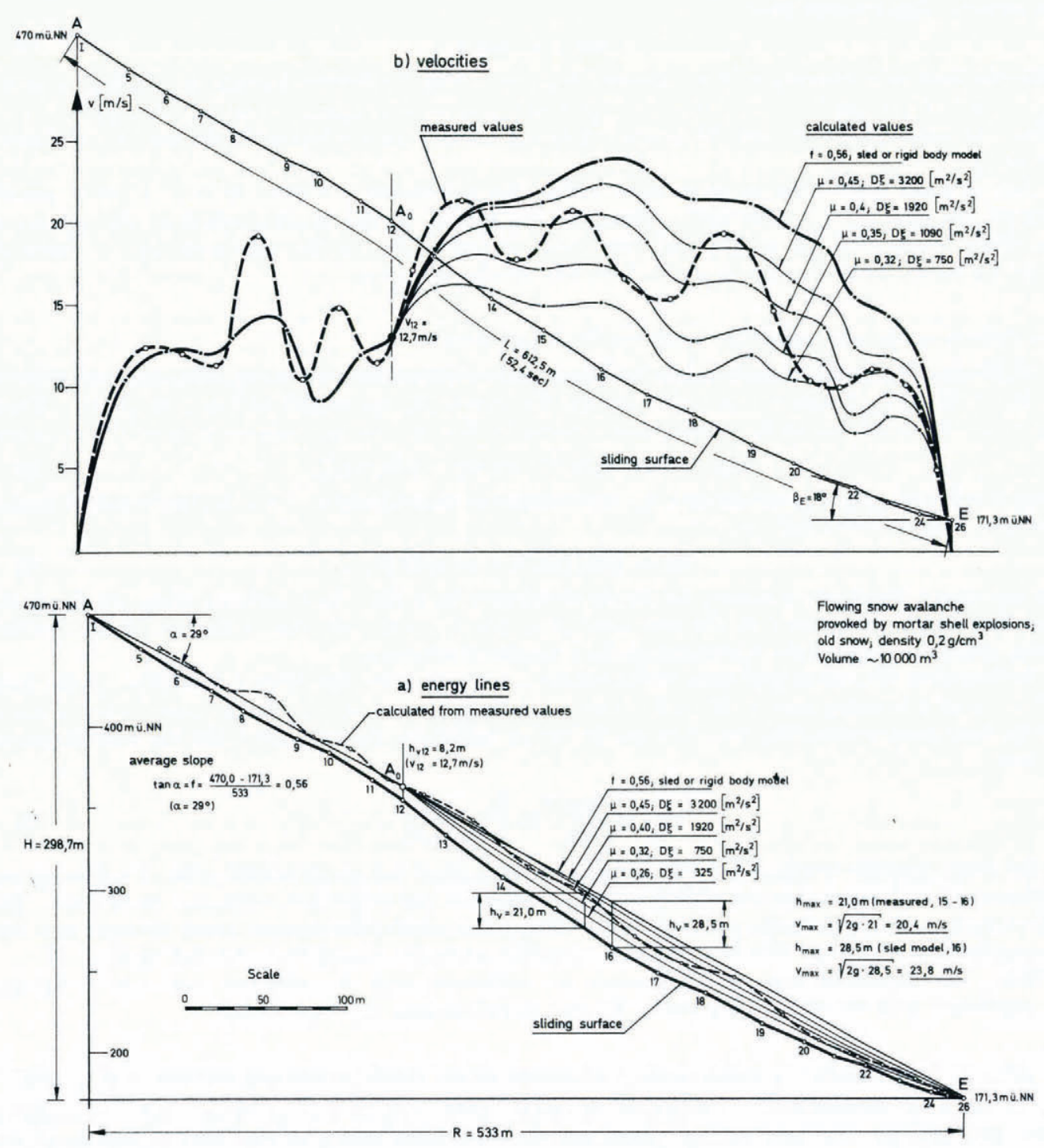

Fig. 2. Example of application: flowing snow avalanche of 30 March 1965, 10 ooo $\mathrm{m}^{3}$ in volume; profile and measured velocity data after Bryukhanov. Calculated energy lines and velocity distribution.

The average slope in the example in Figure 2 is

$$
f_{\mathrm{r}}=H / R=298.7 / 533=0.5^{6} \quad\left(\alpha=29^{\circ}\right) .
$$

From point $A$ to point $A_{0}$ (path station 12), the measured velocities agree quite well with the figures resulting from the straight energy line of the sled model. On this basis, maximum velocity should occur where the tangent parallel to the travel slope touches the slide path (at point $\mathrm{T}$ in Fig. $\mathrm{I}$ ). In the example in Figure 2, this would be the case at path station 16 , for which the velocity head $h_{v} \max =28.5 \mathrm{~m}$ can be measured. It follows that

$$
v_{\max }=\left(2 g_{28.5}\right)^{t}=23.8 \mathrm{~m} / \mathrm{s} .
$$


The actual maximum velocity measured, however, was below path station 13 , where $v=21.2 \mathrm{~m} / \mathrm{s}$ was observed (see Fig. 2b). At point $A_{0}$ (path station I 2), where the steeper profile dip begins and where the curve of measured velocities intersects that of the velocity distribution for the sled model $\left(v_{12}=12.7\right.$ $\mathrm{m} / \mathrm{s})$, the calculation was started on the basis of the two-coefficient model, as described by Körner (1976). The calculated energy lines can be seen in Figure $2 a$ and the velocity distributions with their pairs of values of $\mu$ and $D_{t} \xi$ in Figure $2 b$.

The agreement between the measured and calculated lines is not satisfactory, owing to the pulsation of the front velocities. In order to assess the significant coefficients for the calculation section $\mathrm{A}_{0}-\mathrm{E}$, the velocity distribution for the measured values must therefore be smoothed out. With $D_{\mathrm{f}}=\mathrm{I} \mathrm{m}$, the following estimated values are then obtained:

$$
\mu=0.37 ; \quad \xi=1400 \mathrm{~m} / \mathrm{s}^{2} .
$$

From the velocity distribution which can be worked out on the basis of these values, a fairly constant maximum flow velocity of $19 \mathrm{~m} / \mathrm{s}$ is obtained between path stations 13 and 17 .

\section{Final Remarks}

The energy-line method shows clearly the effect of the path profile shape on avalanche movement. It shows that the models for avalanche dynamics are not in competition but complement each other without inconsistencies. Moreover, the method is useful for model-making, as two movement processes are similar to one another if their energy lines are similar.

\section{REFERENGES}

Bryukhanov, A. V. 1968. Stéréophotogrammétrie terrestre à cadence rapide des avalanches de neige. Société Française de Photogrammétrie. Bulletin, No. 29, p. 9-28.

Bryukhanov, A. V., and others. 1967. On some new approaches to the dynamics of snow avalanches, by A. V. Bryukhanov [and 6 others]. (In Oura, H., ed. Physics of snow and ice: international conference on low temperature science. ... 1966. ... Proceedings, Vol. 1, Pt. 2. [Sapporo], Institute of Low Temperature Science, Hokkaido University, p. 1223-41.)

Heim, A. 1932. Bergsturz und Menschenleben. Zürich, Verlag Fretz und Wasmuth.

Körner, H. J. 1976. Reichweite und Geschwindigkeit von Bergstürzen und Fliessschneelawinen. Rock Mechanics, Vol. 8, No. 4, p. 225-56.

Körner, H. J. r 977 . Lignes d'énergie et vitesse de l'avalanche. Neiges et Avalanches (Grenoble), No. 14, p. 33-45.

Lied, K., and Bakkehøi, S. I 980 . Empirical calculations of snow-avalanche run-out distance based on topographic parameters. Fournal of Glaciology, Vol. 26, No. 94, p. $165-77$.

Scheidegger, A. E. 1973. On the prediction of the reach and velocity of catastrophic landslides. Rock Mechanics, Vol. 5 , No. 4, p. $231-36$.

Scheller, E. Unpublished. Geophysikalische Untersuchungen zum Problem des Taminser Bergsturzes. [Dr. sc. nat. thesis, Eidg. Technische Hochschule Zürich, 1970. Available on request, Diss. ETH Nr. 456o.]

Voellmy, A. 1955. Ưber die Zerstörungskraft von Lawinen. Schweizerische Bauzeitung, Jahrg. 73, Ht. 12, p. $159-62$; Ht. 15 , p. 2 1 $2-17$; Ht. 17, p. 246-49; Ht. 19, p. $280-85$. 